\section{HISTORIA DE LA INVESTIGACIÓN EN LA SIMBIOSIS LEGUMINOSA- BACTERIA: UNA PERSPECTIVA DIDÁCTICA}

\author{
Marta-Helena Ramírez-Bahena \\ Consejo Superior de Investigaciones Científicas \\ marthah.ramirez@irnasa.csic.es \\ Álvaro Peix \\ Consejo Superior de Investigaciones Científicas \\ alvaro.peix@csic.es \\ Encarna Velázquez \\ Universidad de Salamanca \\ evp@usal.es \\ Eulogio J. Bedmar \\ Consejo Superior de Investigaciones Científicas \\ eulogio.bedmar@eez.csic.eez
}

\begin{abstract}
Cómo citar este artículo/Citation: Ramírez-Bahena, M. H., Peix, A., Velázquez, E. y Bedmar, E. J. (2016). Historia de la investigación en la simbiosis leguminosa-bacteria: una perspectiva didáctica. Arbor, 192 (779): a319. doi: http://dx.doi.org/10.3989/ arbor.2016.779n3009
\end{abstract}

Recibido: 08 marzo 2016. Aceptado: 06 mayo 2016.

RESUMEN: Después de los cereales, las leguminosas constituyen la segunda familia en importancia para la alimentación humana y animal. Sin embargo, en contraste con ellos, las leguminosas son capaces de crecer en suelos áridos, de escasa fertilidad, lo que se debe a su capacidad para establecer asociaciones simbióticas con bacterias del suelo llamadas rhizobia. Estos microorganismos forman unos órganos especiales en las raíces de las leguminosas, los nódulos, donde el dinitrógeno $\left(\mathrm{N}_{2}\right)$ atmosférico se transforma en amonio que se exporta a la planta para su crecimiento. Desde su descubrimiento en los nódulos de las leguminosas hasta nuestros días, el conocimiento de las bacterias capaces de establecer simbiosis con estas plantas ha avanzado en múltiples aspectos. Sobre todo, los avances en las técnicas moleculares de identificación bacteriana y el acceso a lugares inexplorados ha permitido confirmar que la interacción de las leguminosas con los rhizobia es más antigua de lo que se creía y que las bacterias fijadoras de dinitrógeno $\left(\mathrm{N}_{2}\right)$ son más abundantes y diversas de lo que se había pensado. Trataremos de describir la historia de una asociación cuyo desarrollo ha sido, y es, clave en la historia de la humanidad tal como la conocemos ahora.

PALABRAS CLAVE: leguminosa; rizobio; simbiosis; fijación biológica de nitrógeno.

\section{HISTORY OF RESEARCH ON LEGUME-RHIZOBIA SYMBIOSIS: A TEACHING APPROACH}

Copyright: @ 2016 CSIC. Este es un artículo de acceso abierto distribuido bajo los términos de la licencia Creative Commons Attribution (CC BY) España 3.0.

ABSTRACT: After cereals, legumes constitute the second most important family of crops for human and animal consumption. However, in contrast to the former, legumes are capable of growing in arid soils of low fertility, due to their ability to establish symbiotic associations with soil bacteria called rhizobia. These microorganisms form special organs in the roots of legumes called nodules, where atmospheric dinitrogen $\left(\mathrm{N}_{2}\right)$ is transformed into ammonium that is exported to the plant for growth. Since their discovery in legume nodules until today, knowledge of the bacteria capable of establishing symbiosis with these plants has advanced in many aspects. Especially, advances in molecular techniques for bacterial identification and access to unexplored places have confirmed that the interaction of legumes with rhizobia is older, and that $\mathrm{N}_{2}$-fixing bacteria are more abundant and diverse, than considered previously. Here, we attempt to relate the history of an association whose development is key in the history of mankind as we know it now.

KEYWORDS: legume; rhizobia; symbiosis; biological nitrogen fixation. 
Hace más de 10000 años tuvo lugar un cambio radical en el modo de vida de nuestros antepasados, de ser nómadas que recorrían grandes distancias para conseguir su sustento, comenzaron a usar las semiIlas como alimento, se asentaron y se convirtieron en agricultores. Con la agricultura era posible obtener el alimento necesario dentro de un área relativamente pequeña comparada con la extensión de terreno que, como cazadores, debían recorrer para obtener el alimento suficiente. Esto les permitió sustentar a poblaciones cada vez más numerosas, dando lugar a más y más asentamientos que, con el tiempo, dieron origen a las primeras ciudades (Davis, 2007).

Como la sociedad empezó a girar en torno a esta nueva actividad, la supervivencia se supeditó a la obtención de cosechas suficientes para mantener a los pobladores de estas nuevas ciudades. Esto hizo necesario crear formas de control, de buscar la manera de crear registros de producción y, poco a poco, se fueron implementando sistemas de organización cada vez más complejos. Así nacieron la escritura, los gobiernos, el comercio y, con éste último, deviene el intercambio cultural, la entrada y salida de nuevos productos, el intercambio de ideas e historias desde lugares más lejanos, y la generación de nuevos conocimientos. Podemos imaginar que, seguramente, el crecimiento de las plantas a partir de semillas se había observado por nuestros antepasados desde hacía más tiempo pero, por alguna razón, se había ignorado durante miles de años. No obstante, cualesquiera que sean las razones de sus orígenes, la agricultura, sin lugar a dudas, permitió el nacimiento de las primeras civilizaciones.

Actualmente, la agricultura mantiene un papel elemental en la supervivencia de nuestra sociedad, y la obtención de alimento a partir de las cosechas continúa siendo la preocupación de todos los gobiernos. Desde los inicios de la agricultura en las distintas partes del mundo, las principales cosechas las constituyen los cereales y las leguminosas. Los informes de 2015 de la Food and Agriculture Organization of the United Nations (FAO) muestran que los cereales (trigo, arroz, cebada, maíz, centeno, avena, mijo, etc.) constituyen la parte mayoritaria de la producción del sector agrario y son la fuente más importante de alimento para el consumo humano; a los cereales le siguen las leguminosas (soja, alubia, cacahuete, garbanzo, lenteja, haba, etc.), que juegan también un papel crucial en la alimentación humana, en la seguridad nutricional y en los ecosistemas agrícolas (Bedmar, González, Lluch y Rodelas, 2006).
Ahora bien, siendo la agricultura de vital importancia para la sociedad desde tiempos ancestrales, se han desarrollado distintas técnicas para la obtención de más y mejores cosechas (Frioni, 1990). Un ejemplo es la rotación de cultivos, técnica que consiste en alternar el cultivo de distintas plantas en el mismo suelo cada año, habitualmente cereales y leguminosas. De forma empírica nuestros antepasados aprendieron que incluir leguminosas mejoraba las condiciones del suelo y que con esta técnica se evitaba su desgaste y, además, se prevenían plagas o enfermedades de las plantas. El secreto del éxito de la rotación de cultivos con leguminosas tardó varios siglos en desvelarse ya que, para conocer lo que se escondía detrás del mismo, tuvieron que ocurrir una serie de sucesos históricos que permitieron desarrollar las herramientas necesarias para ahondar en un mundo invisible y desconocido, y de esta forma sentar las bases de la Microbiología como ciencia. En 1675, con la invención del microscopio por Anton van Leeuwenhoek, los microorganismos, esos seres invisibles que causaban enfermedades según Francastoro en 1546, y de los que muchos filósofos hablaban en sus discursos, comenzaron a tomar forma (Prescott, Harley y Klein, 2004).

La Royal Society de Londres difundió las descripciones hechas por Leeuwenhoek de sus observaciones al microscopio, y son tan detalladas que es posible saber que los "animálculos", como él los Ilamó, no eran otra cosa que bacterias y protozoos. Leeuwenhoek también demostró que tales animálculos eran abundantes, diversos y que era posible encontrarlos prácticamente en todos los lugares (Brock, 1961; Collard, 1976). Por otra parte, el desarrollo de la esterilización, la obtención de cultivos puros de microorganismos, el perfeccionamiento del microscopio, así como el golpe definitivo que asestó Pasteur en 1861 a la teoría de la generación espontánea, que afirmaba que los organismos vivos podían originarse a partir de materia no viva, fueron cruciales en el avance de esta nueva ciencia. Con estas herramientas básicas se inició la exploración del mundo microbiano y se desarrolló el interés por determinar la relación de los microorganismos con el resto de los seres vivos (Schlegel, 1990)

Los trabajos de investigación de Beijerinck y Winogradsky dirigidos a dilucidar el papel que desempeñan las bacterias en determinados procesos biogeoquímicos permitieron el desarrollo de los medios selectivos y de enriquecimiento, con lo que fue posible aislar microorganismos capaces de utilizar deter- 
minados nutrientes del medio. Estos descubrimientos constituyeron una poderosa herramienta para el estudio de distintos grupos microbianos y dio origen a numerosos descubrimientos que, a su vez, sentaron las bases para nuevas investigaciones. Los avances de la microbiología continuaron y con ellos, poco a poco, se esclareció el misterio de cómo las leguminosas enriquecían los suelos de cultivo. A ello contribuyó que ya se sabía que el nitrógeno (N) es un factor limitante de la producción vegetal, por lo que muchos estudios se dirigieron a entender su movilización dentro de los ecosistemas.

A mediados del siglo XIX, los experimentos de Boussingault mostraron que las leguminosas asimilaban (fijaban) el nitrógeno de la atmósfera donde se encuentra en forma de $\mathrm{N}_{2}$, y Woronin, en 1866, descubrió las bacterias que se albergaban en los nódulos de sus raíces. En 1879, los experimentos de Frank pusieron de manifiesto que ciertas bacterias del suelo y plantas leguminosas se relacionaban de alguna forma, ya que esas bacterias eran capaces de inducir la formación de más nódulos. Con todas estas observaciones, y después de la introducción del concepto de simbiosis por De Bary en 1878, Schindler (1885) fue el primero en describir que los nódulos radicales eran el resultado de la simbiosis entre la planta y la bacteria. Ward (1877) dio un paso más al lograr la formación de nódulos en suelo estéril inoculando semillas con bacterias procedentes de nódulos triturados, y describió el proceso de infección. Durante su búsqueda de bacterias asimiladoras de $\mathrm{N}_{2}$, Winogradsky, en 1890, logró explicar el ciclo del $\mathrm{N}$ en la naturaleza, y Beijerinck, en 1908, demostró por métodos químicos que la bacteria Azotobacter incorpora el $\mathrm{N}_{2}$ de la atmósfera mientras crece.

Resumiendo lo anterior, hasta ese momento se sabía: (i) que las plantas leguminosas asimilaban $\mathrm{N}_{2}$ de la atmósfera, (ii) que estas mismas plantas albergaban bacterias en sus nódulos radicales, (iii) que estas bacterias infectaban a otras plantas leguminosas y generaban la formación de más nódulos, y (iv) que existían bacterias asimiladoras de $\mathrm{N}_{2}$ en vida libre. Estos resultados generaron variedad de opiniones, a veces opuestas, entre la comunidad científica acerca de las funciones de los nódulos en las raíces de las leguminosas. Entre esas opiniones se consideraba la posibilidad de que las bacterias de los nódulos fueran las responsables de la asimilación del nitrógeno del aire y, si era así, se preguntaba si el proceso se limitaba a las leguminosas o si habría otras plantas capaces de llevarlo a cabo.
Fueron Hellriegel y Wilfarth, en 1888, quienes demostraron de forma definitiva la existencia de asimilación de $\mathrm{N}_{2}$ por las bacterias en su asociación con leguminosas. Sus experimentos demostraron que las leguminosas se comportan de forma diferente a las gramíneas en presencia de nitrógeno, ya que a) mientras que el crecimiento de las gramíneas está limitado por la presencia de $\mathrm{N}$ asimilable en el suelo, las leguminosas utilizan una segunda fuente con la que pueden satisfacer las necesidades de este elemento, b) que esa fuente de $\mathrm{N}$ no puede ser otra que el $\mathrm{N}_{2}$ que se encuentra en la atmósfera, c) que el proceso sólo ocurre cuando existe una simbiosis entre la leguminosa y bacterias específicas del suelo, y d) que la asimilación del nitrógeno atmosférico ocurre en los nódulos radicales. Aunque Hellriegel y Wilfarth demostraron la implicación de las bacterias en la asimilación del $\mathrm{N}_{2}$ por la planta, la controversia continuó hasta que Beijerinck, en el mismo año, logró aislar y cultivar microorganismos a partir de nódulos esterilizados en superficie de varias leguminosas. Así, obtuvo diferentes cultivos que, además, no eran capaces de asimilar $\mathrm{N}_{2}$ en vida libre. La prueba definitiva, no obstante, la obtuvo en 1890 con el aislamiento de bacterias a partir de nódulos de las raíces de haba (Vicia faba) que utilizó para inocular plantas de haba para generar en las mismas la formación de nódulos radicales, con lo que demostró que la asimilación de $\mathrm{N}_{2}$ era posible en la asociación bacteria-planta, proceso al que se conoce ahora como fijación biológica de nitrógeno. Todos las bacterias aisladas por Beijerinck en 1888 fueron clasificadas por él mismo como Bacillus radicicola y reclasificadas por Frank en 1889 como Rhizobium leguminosarum, nombre con el que se le conoce hasta la fecha, y es la especie tipo del género Rhizobium.

La continuación de la investigación sobre la simbiosis rizobio-leguminosa permitió describir la existencia en el interior de los nódulos de unas células especializadas denominadas bacteroides (Prazmowski, 1890) y de una clara relación entre la formación de bacteroides y la asimilación de $\mathrm{N}_{2}$ (Nobbe y Hiltner, 1893). Con esta información ya era posible afirmar que las leguminosas establecen simbiosis con ciertos microorganismos diazotróficos (literalmente "que se alimentan de nitrógeno") que son los responsables de la asimilación del $\mathrm{N}_{2}$ atmosférico, y que gran parte de ese $\mathrm{N}$ pasa al suelo donde el siguiente cultivo puede aprovecharlo. Se pudo así, finalmente, entender el éxito ancestral de la rotación de cultivos y conocer la razón por la que las leguminosas son plantas que fertilizan el suelo donde se cultivan. 
Aparentemente, esta historia podría haber terminado aquí, pero solo era el principio, ya que todos estos estudios conformaron la base de posteriores investigaciones sobre la simbiosis leguminosa-bacteria, que ha resultado ser mucho más compleja de lo que cualquiera podría haber imaginado. Después de que Beijerinck obtuviera el primer cultivo puro a partir de nódulos de leguminosas parecía que la mayoría de los investigadores coincidían en que los microorganismos que producían nódulos podrían formarlos en cualquier leguminosa, y que además se trataba siempre del mismo tipo de bacterias. Sin embargo, los trabajos de Hellriegel y Wilfarth contradecían lo anterior, ya que los microorganismos aislados de los nódulos de una leguminosa no podían infectar siempre a cualquier leguminosa.

Con el tiempo resultó evidente que algunos aislados estaban limitados a cierto grupo de leguminosas (espectro de hospedador muy estrecho), mientras que otros podían nodular a más de una especie de leguminosa (espectro de hospedador muy amplio). Estas observaciones dieron lugar al concepto de "grupos de inoculación cruzada" (Baldwin y Fred, 1929), que se utilizó para organizar estas bacterias, ahora conocidas comúnmente como rhizobia o rizobios, en grupos sobre la base de las leguminosas que cada uno de ellos podía nodular. Esta forma de agrupar a los rhizobia fue y sigue siendo una práctica común para asegurar que una mezcla de rhizobia sea eficaz en la nodulación cuando se aplica a un cultivo.

En los inicios del siglo XX era indispensable conocer los grupos de inoculación cruzada a los que pertenecían los rhizobia utilizados como inoculantes, ya que el uso de fertilizantes químicos no se había generalizado aún, y la agricultura era todavía dependiente del uso de las leguminosas para mantener la fertilidad del suelo o del uso de estiércol y residuos vegetales para abastecer las necesidades de $\mathrm{N}$ de sus cultivos. Con la llegada de la revolución verde a mediados del siglo XX y la aparición de abonos químicos se perdió, de forma paulatina, la necesidad de utilizar los rizobios como fertilizantes. No obstante, la necesidad de alimentar a una población cada vez más abundante ha ocasionado el empleo masivo de fertilizantes químicos que, junto a plaguicidas y herbicidas, ha resultado en la contaminación de aguas y sedimentos, erosión de los suelos, e incluso daños a la salud humana. Esta situación ha ocasionado el auge de la agricultura biológica que trata de prescindir al máximo de cualquier producto químico, lo que ha revitalizado tanto el interés en la rotación de cultivos como las prácticas de inoculación.
Actualmente, se sabe que más de la mitad de todo el $\mathrm{N}$ incorporado en los sistemas terrestres es resultado de la fijación biológica de nitrógeno en simbiosis. Dicho de otra manera, el nutriente fundamental para el desarrollo vegetal y el de todos los seres vivos, es transformado de una forma inerte $\left(\mathrm{N}_{2}\right)$ en formas asimilables por los organismos, con lo que se mantiene el equilibrio de los ecosistemas. No es de extrañar, por tanto, que la creciente preocupación por la conservación de los ecosistemas del planeta y la implantación de actividades agrícolas respetuosas con el medioambiente, hagan que los estudios sobre la simbiosis leguminosa-bacteria se consideren de gran relevancia en la actualidad.

El interés en el estudio de esta simbiosis no estriba únicamente en su papel ecológico en los sistemas agroforestales, sino además en la importancia de las leguminosas a nivel económico y cultural. Las leguminosas representan la tercera familia más grande de plantas con flor de las que se conocen alrededor de 727 géneros y casi 20000 especies. Estas plantas son tan diversas que, entre sus miembros, podemos encontrar pequeñas hierbas, arbustos, enredaderas, árboles gigantes y hasta algunas plantas acuáticas. Constituyen los componentes principales de la mayoría de los tipos de vegetación del mundo; además su capacidad de fijar $\mathrm{N}_{2}$ en simbiosis con los rhizobia les proporciona la ventaja de colonizar suelos en los que otro tipo de plantas no podrían asentarse fácilmente. De ahí, su importante papel ecológico y su protagonismo en la restauración de ecosistemas.

Al mismo tiempo, desde hace milenios, el hombre utiliza los productos derivados de las leguminosas de múltiples maneras y contribuyen en gran medida a la economía mundial. No sólo se utilizan como alimento para los animales y los seres humanos sino también en la preparación de bebidas, nutraceúticos, productos farmacéuticos y procesos biotecnológicos. Además, se aprovechan las enzimas que producen, se emplean en el control de plagas, como fertilizantes, en la industria minera, en la elaboración de celulosa y producción de biodiesel, en la construcción y en el ecoturismo. Todo ello sin olvidar que han sido clave en la historia de la ciencia ya que los guisantes (Pisum sativum) fueron el material utilizado por Mendel en 1865 para dilucidar las leyes de la herencia y ser reconocido como el padre de la Genética. Las leguminosas guardan tal relación con el hombre que, a nivel global, se les otorga tanta importancia como a las gramíneas, incluso supera a éstas últimas en relación a la variedad de usos que se les da. Ciertamente, la importancia a nivel mundial de 
las leguminosas en distintos aspectos ha contribuido a que el estudio de la simbiosis leguminosa-bacteria siga en auge, extendiéndose de las leguminosas más comunes en la alimentación humana y animal a otras especies de interés agronómico, industrial y biotecnológico que puedan localizarse en los diferentes ecosistemas, principalmente los tropicales.

Desde finales del siglo XIX, la Microbiología hizo posible el aislamiento de gran variedad de microorganismos, por lo que se hizo necesario crear un marco taxonómico para encuadrar a los organismos que se describían. Cohn (1875) y Migula (1897) Ilevaron a cabo los primeros esfuerzos sustentando el concepto de especie predominantemente sobre caracteres morfológicos. Poco a poco se hizo evidente que este tipo de clasificación era insuficiente, por lo que se introdujeron, además, características bioquímicas (Orla-Jensen, 1909), así como rasgos patogénicos y de tinción (Buchanan, 1915). El sistema de taxonomía bacteriana comenzó a consolidarse con la 1ạ edición del "Bergey's Manual of Determinative Bacteriology" (1923), así como con las propuestas de Kluyver y van Niel publicadas como "Prospects for a Natural System of Classification of Bacteria" (1936). Pero el gran avance en taxonomía bacteriana se produjo con la inclusión de los criterios filogenéticos propuestos por Woese y Fox (1977), que demostraron que las estructuras y secuencias moleculares (genotipo) son más reveladoras de las relaciones evolutivas que el uso de características morfológicas clásicas (fenotipo). De este modo, el gen ribosómico $16 \mathrm{~S}$ se convirtió en la principal herramienta taxonómica utilizada en la última edición del Bergey's Manual finalizada en 2012, que consta de cinco volúmenes con información descriptiva de la sistemática, la fisiología, la ecología y los hábitats de los distintos grupos de procariotas descritos hasta ese momento.

Con el establecimiento de una taxonomía bacteriana más sólida, así como con la inclusión de las nuevas herramientas de la biología molecular, se ha constatado la gran biodiversidad de los rhizobia, de los que ya se han descrito unas 200 especies diferentes incluidas en, al menos, 20 géneros y distribuidas en dos clases, Alfaproteobacteria y Betaproteobacteria (Peix, RamírezBahena, Velázquez y Bedmar, 2015). Es opinión generalizada entre los investigadores que el número seguirá en aumento, no solo por la rapidez con la que es posible identificar nuevas especies bacterianas sino por el hecho de que en la mayoría de los rhizobia la información genética necesaria para llevar a cabo la fijación de $\mathrm{N}_{2}$ (genes nif), así como la nodulación (genes nod), se encuentra en plásmidos o islas simbióticas. Este material, en determinadas circunstancias, puede transferirse de una bacteria a otra (transferencia horizontal) y además expresarse, generando nuevas cepas capaces de fijar $\mathrm{N}_{2}$ en simbiosis con leguminosas.

Justamente, la forma en la que se establece la simbiosis desde un punto de vista bioquímico, así como el comportamiento de los plásmidos, han sido otros de los aspectos más estudiados de la simbiosis leguminosa-bacteria, sobre todo desde el surgimiento de la genética molecular en la segunda mitad del siglo XX. Los experimentos de Avery, McLeod y McCarty en 1944, que demostraron que el "principio transformador" es el ADN, junto a la determinación de su estructura en 1953 por Watson y Crick, fueron los principales eventos que constituyeron el inicio de esta nueva ciencia. La Genética ha permitido conocer procesos fundamentales de la célula como la regulación de la expresión o los mecanismos de transferencia y recombinación génicas. Además, con el desarrollo de la ingeniería genética y la secuenciación de $A D N$, ha sido posible profundizar y ampliar el conocimiento sobre éstos y otros procesos celulares. Los avances de la genética han sido tales que ya en 1995 se publicó la primera secuencia completa del genoma de la bacteria Haemophilus influenzae, y hasta la fecha, se han secuenciado más de 45000 genomas bacterianos completos según la Genomes On Line Database (GOLD).

Los estudios genéticos sobre la relación leguminosabacteria se centraron en la búsqueda de los genes bacterianos involucrados en la simbiosis y, en un principio, Balassa (1954) y Kowalski (1967) describieron la transferencia de información genética entre los rhizobia. Higashi, también en 1967, estableció que la capacidad de nodulación entre rhizobia puede transferirse mediante plásmidos. Nuti, en 1977, puso de manifiesto la presencia de grandes plásmidos en distintas especies de Rhizobium. En 1981, Török y Kondorosi obtuvieron la secuencia de nucleótidos del gen de la nitrogenasa reductasa (nifH), enzima responsable de la fijación de $\mathrm{N}_{2}$. En 1985, Downie y colaboradores, junto con Egelhoff y Long, identificaron los genes responsables de la nodulación (nodABC). A partir de 1986 se profundizó en el estudio de las flavonas, moléculas que inducen la expresión de los genes de nodulación (Peters, Frost y Long, 1986; Horvath, Bachem, Schell, y Kondorosi, 1987), y se observó que los productos de estos genes estimulan la mitosis en las células de la planta que darán lugar a la formación del nódulo (Schmidt, Wingender, John, Wieneke y Schell, 1988, Faucher et al., 1988; Schlaman, Spaink, Okker, y Lugtenberg, 1989). También se demostró que ciertos po- 
lisacáridos producidos por las bacterias juegan un papel fundamental en la unión de las mismas a las raíces de las leguminosas (Glazebrook y Walker 1989; Lerouge et al. 1990). Algunos investigadores, por otra parte, pusieron a prueba el establecimiento de la simbiosis leguminosabacteria ante ciertas condiciones de estrés abiótico (Graham, 1992), lo que demostraba tanto la influencia de los factores ambientales sobre la misma como la capacidad de adaptación de las bacterias.

Muchas de las investigaciones realizadas a lo largo de la última década del siglo $X X$ se centraron en el esclarecimiento de las funciones de los genes de nodulación (nod) y fijación de nitrógeno (nif), en los productos que formaban, en cómo actuaban sobre la planta así como en su localización en las distintas especies de rhizobia (Charles y Finan, 1990; Krishnan y Pueppke 1991; Price et al. 1992; Agron, Ditta y Helinski, 1992; Freiberg et al. 1997; Jabbouri et al. 1998). Entonces, cuando parecía que los genes nod eran la clave, Giraud y colaboradores descubrieron en 2007 que existen ciertas cepas de rhizobia fotosintéticas del género Bradyrhizobium que no poseen estos genes y que, además, no requiere de los productos de los mismos para establecer la simbiosis. Estos hechos indican, sin lugar a dudas, que la relación leguminosabacteria no deja de ser sorprendente.

Igualmente, el estudio de genes individuales demostró el interés sobre el estudio de la información genética en conjunto. De esta manera, Kündig, Hennecke y Göttfert, (1993) comenzaron las aproximaciones para obtener el genoma completo de Bradyrhizobium japonicum, mientras que Honeycutt, McClelland y Sobral (1993), se centraron en el de Rhizobium meliloti (hoy Ensifer meliloti).

En 1997, Yanni y colaboradores descubrieron algo que pocos habían imaginado; algunos rhizobia podían encontrarse dentro de las raíces de plantas de arroz (endofitos), y los estudios de Biswasa, Ladhaa y Dazzob (2000) confirmaron que, además, esos rhizobia actuaban como promotores del crecimiento vegetal en las mismas plantas. Estos resultados pusieron de manifiesto la increíble versatilidad de los rhizobia y que los beneficios que pudieran ofrecer a las plantas no estaban reservados sólo a las leguminosas, sino también a los cereales, por lo que en un futuro las posibilidades de su uso en la agricultura podrían multiplicarse. De hecho, recientemente, GarcíaFraile et al. (2012) mostraron este potencial de los rhizobia como inoculantes en plantas no leguminosas, como tomate y pimiento, demostrando que algunas cepas seleccionadas eran capaces tanto de mejorar el rendimiento del cultivo como su calidad nutricional.
Al inicio del nuevo siglo XXI los rhizobia no quedaron fuera de la emergente era genómica y la obtención de genomas completos, por lo que algunas de las principales especies fueron las primeras en ser secuenciadas, entre ellas Mesorhizobium loti, el simbionte de Lotus, en el año 2000, Ensifer meliloti, que se asocia con la alfalfa, en 2001, y Bradyrhizobium japonicum, que forma nódulos con la soja, en 2002. En conjunto, con los avances de la ingeniería genética, los estudios fueron cada vez más complejos, y casi cada nuevo descubrimiento que se hacía daba pie a la creación de nuevas líneas de investigación. A lo largo de estos estudios se ha puesto en evidencia el hecho de que la asociación entre los rhizobia y las raíces de las leguminosas es específica, con un reconocimiento mutuo de los dos organismos compatibles resultado de una compleja secuencia de interacciones a nivel molecular, que da lugar a una respuesta quimiotáctica y una unión específica a las estructuras radicales. La asociación se caracteriza por el desarrollo de nódulos, que son órganos simbióticos altamente especializados con estructura y organización únicas.

Sin duda, una de las más importantes contribuciones de la biología molecular al estudio de la relación leguminosa-bacteria, ha sido la inclusión en la taxonomía de los rhizobia el análisis de marcadores filogenéticos como los genes ribosómicos $16 \mathrm{~S}$ y los denominados "housekeeping", principalmente atpD y recA (Vinuesa et al. 2005). Esto ha permitido aclarar el estatus taxonómico no sólo de nuevos aislados de rhizobia, sino también de aquellos que fueron aislados en las primeras investigaciones realizadas con estas bacterias como es el caso de $R$. leguminosarum (Ramírez-Bahena et al. 2008). Los conocimientos generados mediante el uso de las herramientas moleculares han propiciado la creación de nuevos conceptos dentro de la interacción leguminosa-bacteria, como es el caso del término "simbiovar" (o simbiovariedad) propuesto por Rogel y colaboradores en 2011, que se define de acuerdo con la secuencia de sus genes simbióticos, sustituyendo a los términos "variedad" o "biovariedad" que, basados en el espectro de hospedador, se utilizan desde hace siglos.

La especificidad de los rhizobia para nodular una leguminosa está codificada en elementos genéticos susceptibles de ser transferidos entre especies e, incluso, entre géneros, y esta capacidad para transferirse horizontalmente determina el espectro de hospedador de un rizobio. Esta transferencia génica permitiría a cepas de distintas especies, que pertenecen a la misma simbiovariedad, nodular la misma leguminosa y que 
una misma especie de rhizobia que contenga cepas pertenecientes a diferentes simbiovariedades pueda nodular a diferentes leguminosas. Por otra parte, las leguminosas pueden tener diferente grado de especificidad de modo que leguminosas muy promiscuas pueden formar nódulos con cepas de rhizobia de diferentes simbiovariedades, mientras que aquellas que son muy restrictivas sólo pueden formar nódulos con una única simbiovariedad. Para explicarlo de un modo más sencillo, puede ser adecuada la analogía de una llave-cerradura, donde una cerradura con una amplia abertura para la llave (leguminosas promiscuas), permiten la entrada de varios tipos de llaves, que por el hecho de entrar en la cerradura son capaces de accionar el mecanismo de apertura, como las cerraduras antiguas, mientras que cerraduras con una estrecha abertura para la llave (leguminosas restrictivas), como las cerraduras de seguridad actuales, sólo es posible

\section{AGRADECIMIENTOS}

Los autores agradecen al gobierno de España la concesión de los diferentes proyectos de investigación que les han permitido estudiar diferentes aspectos de la asociación simbiótica rhizobia-leguminosa a lo largo de su actividad profesional. Este agradecimiento se hace extensivo a la Junta de Castilla y León y a la Junta de Andalucía que también han subvencionado la investigación realizada.

\section{BIBLIOGRAFÍA}

Agron, P. G., Ditta, G. S. y Helinski, D. R. (1992). Mutational analysis of the Rhizobium meliloti nifA promoter. Journal of Bacteriology, 174 , pp. 4120-4129.

Balassa, R. (1954). Transformation mechanisms of Rhizobia. I-III. Acta microbiologica Academiae Scientiarum Hungaricae Magyar Tudományos Akadémia, 2, 1-2, pp. 51-78.

Balassa, G. (1963). Genetic transformation in Rhizobium: A review of the work of R. Balassa. Bacteriological Reviews, 27, pp. 228241.

Baldwin, I. L. y Fred, E. B. (1929). Nomenclature of the root-nodule bacteria of Leguminosae. Journal of Bacteriology, 17, pp. 141150.

Bedmar, E. J., González, J. J., Lluch, C. y Rodelas, B. (2006). Fijación de Nitrógeno: Fundamentos y Aplicaciones. Sociedad Española de Fijación de Nitrógeno.

Beijerinck, M. W. (1888). Cultur des Bacillus radicicola aus den Knöllchen. Botanishe Zeitung, 46, pp. 740-750.

Biswasa, J. C., Ladhaa, J. K. y Dazzob F. B. (2000). Rhizobia inoculation improves nutrient uptake and growth of lowland rice. Soil abrirlas con un tipo de llave específico. De una u otra forma, la presencia de simbiovariedades en rhizobia refleja una co-evolución bacteria-planta, y el estudio de las mismas en los rhizobia es fundamental a nivel práctico, ya que de ello depende un buen empleo como biofertilizante.

Evidentemente, las leguminosas y sus endosimbiontes (rhizobia) serán objeto de estudio en los años venideros y con la llegada de la era genómica y sus distintas ramas, entre ellas la metagenómica, la proteómica y la transcriptómica, las posibilidades de estudio se multiplican exponencialmente. Este texto ha pretendido ofrecer una modesta aproximación a la historia, hasta la fecha, de los estudios dirigidos a comprender la significativa relación leguminosa-bacteria, que resulta cada vez más sorprendente y que, sin duda, aún no ha terminado de escribirse.
Science Society American Journal, 64, pp. 1644-1650. http:// dx.doi.org/10.2136/sssaj2000.6451644x

Brock, T. D. (1961). Milestones in Microbiology. Englewood Cliffs: Prentice-Hall. Disponible en: https://archive.org/details/MilestonesinMicrobiology.

Buchanan, R. E. (1915) Nomenclature of the Coccaceae. Journal of Infectious Diseases, 17, pp. 528-541. http://dx.doi.org/10.1093/ infdis/17.3.528

Charles, T. C. y Finan, T. M. (1990). Genetic map of Rhizobium meliloti megaplasmid pRme SU47b. Journal of Bacteriology, 172, pp. 2469-2476.

Cohn, F. (1875). Untersuchungen ueber Bakterien. Beitraege zur Biologie der Planzen. En: Brock, T. D. (1961). Milestones in Microbiology. Englewood Cliffs: Prentice-Hall, pp. 127-222. Disponible en: https://archive.org/details/MilestonesinMicrobiology.

Collard, P. (1976). The Development of Microbiology. Cambridge, London: Cambridge University Press.

Davis, J. C. (2007). La increíble historia de la humanidad: de la Edad de Piedra a nuestros tiempos. Barcelona: Planeta. 
Downie, J. A., Knight, C. D., Johnston, A. W. B. y Rossen, L. (1985). Identification of genes and gene products involved in the nodulation of peas by Rhizobium leguminosarum. Molecular General Genetics, 198, pp. 255-262. http://dx.doi.org/10.1007/ BF00383003

Egelhoff, T. T. y Long, S. R. (1985). Rhizobium meliloti nodulation genes: identification of nodDABC gene products, purification of NodA protein, and expression of nodA in Rhizobium meliloti. Journal of Bacteriology, 164, pp. 591-599.

FAO Statistical Pocketbook (2015). Disponible en: http://www.fao. org/3/a-i4691e.pdf

Faucher, C., Maillet, F., Vasse, J., Rosenberg, C., van Brussel, A. A. N., Truchet, G. y Dénarié, J. (1988). Rhizobium meliloti host range nod $H$ gene determines production of an alfalfa-specific extracellular signal. Journal of Bacteriology, 170, pp. 5489-5499.

Frank, B. (1889). Ueber die Pilzsymbiose der Leguminosen. Berichte der Deutschen Chemischen Gesellschaft, 7, pp. 332-346.

Freiberg, C., Fellay, R., Bairoch, A., Broughton, W. J., Rosenthal, A. y Perret, X. (1997). Molecular basis of symbiosis between Rhizobium and legumes. Nature, 387, pp. 394-401. http://dx.doi. org/10.1038/387394a0

Frioni, L. (1990). Ecología Microbiana del Suelo. Montevideo: Universidad de la República.

Glazebrook, J. y Walker, G. C. (1989). A novel exopolysaccharide can function in place of the calcofluor-binding exopolysaccharide in nodulation of alfalfa by Rhizobium meliloti. Cell, 56, pp. 661672. http://dx.doi.org/10.1016/00928674(89)905886

Giraud, E., Moulin, L., Vallenet, D., Barbe, V., Cytryn, E., Avarre, J. C., Jaubert, M., Simon, D., Cartieaux, F., Prin, Y., Bena, G., Hannibal, L., Fardoux, J., Kojadinovic, M., Vuillet, L., Lajus, A., Cruveiller, S., Rouy, Z., Mangenot, S., Sequrens, B., Dossat, C., Frank, W. L., Chang. W. S., Saunders, E., Bruce, D., Richardson, P., Normand, P., Dreyfus, B., Pignol, D., Stacey, G., Emerich, D., Vermeglio, A., Médique, Cy Sadowsky, M. (2007). Legumes symbioses: absence of nod genes in photosynthetic bradyrhizobia. Science, 316, pp. 1307-1312. http://dx.doi.org/10.1126/science.1139548

García-Fraile, P., Carro, L., Robledo, M., Ramírez-Bahena, M. H., Flores-Félix, J. D., Fernández, M. T., Mateos, P. F., Rivas, R., Igual, J. M., Martínez-Molina, E., Peix, A. y Velázquez, E. (2012). Rhizobium promotes non-legumes growth and quality in several production steps: towards a biofertilization of edible raw vegetables healthy for humans. PLoS ONE 7, e38122. http://dx.doi. org/10.1371/journal.pone.0038122

Graham, P. H. (1992). Stress tolerance in Rhizobium and Bradyrhizobium, and nodulation under adverse soils conditions. Canadian Journal of Microbiology, 38, pp. 475-484. http://dx.doi. org/10.1139/m92079

Hellriegel, H. y Wilfarth, H. (1888). Untersuchungen über die Stickstoffnahrung der Gramineon und Leguminosen. Berlin: Buchdruckerei der "Post" Kayssler. Disponible en: https://archive.org/ details/untersuchungen00hell.

Higashi, S. (1967). Transfer of clover infectivity of Rhizobium trifolii to Rhizobium phaseoli as mediated by an episomic factor. Journal of General and Applied Microbiology, 13, pp. 391-403. http://dx.doi.org/10.2323/jgam.13.391
Honeycutt, R. J., McClelland, M. y Sobral, B.W. (1993). Physical map of the genome of Rhizobium meliloti 1021. Journal of Bacteriology, 175, pp. 6945-6452.

Horvath, B., Bachem, C. W. B., Schell, J. y Kondorosi, A. (1987). Host specific regulation of nodulation genes in Rhizobium mediated by a plant-signal, interacting with the nodD product. EMBO Journal, 6, pp. 841-848.

Jabbouri, S., Relić, B., Hanin, M., Kamalaprija, P., Burger, U., Promé, J. C. y Broughton, W. J. (1998). nolO and noel (HsnIII) of Rhizobium sp. NGR234 are involved in 3-O-carbamoylation and 2-Omethylation of Nod factors. Journal of Biological Chemistry, 273, pp. 12047-12055. http://dx.doi.org/10.1074/jbc.273.20.12047

Kowalski, M. (1967). Transducing phages of Rhizobium meliloti. Acta Microbiologica Polonica, 16, pp. 7-12.

Krishnan, H. B. y Pueppke S. G. (1991). nolC, a Rhizobium fredii gene involved in cultivar-specific nodulation of soybean, shares homology with a heat-shock gene. Molecular Microbiology, 5, pp. 737-745. http://dx.doi.org/10.1111/j.13652958.1991. tb00744.x

Kündig, C., Hennecke, H. y Göttfert, M. (1993). Correlated physical and genetic map of the Bradyrhizobium japonicum 110 genome. Journal of Bacteriology, 175, pp. 613-622.

Lerouge, P., Roche, P., Faucher, C., Maillet, F., Truchet, G., Promé, J. C. y Dénarié, J. (1990). Symbiotic host specificity of Rhizobium meliloti is determined by a sulphated and acylated glucosamine oligosaccharide signal. Nature, 344, pp. 781-784. http://dx.doi. org/10.1038/344781a0

Migula, W. (1897). System der Bakterien. Handbuch der Morphologie, entwicklungsgeschichte und systematik der bakterien (volume 1). Publisher Jena, Fischer. Disponible en: https://archive. org/details/systemderbakter02migugoog

Nobbe, F. y Hiltner, L. (1896). Bodenimpfung für anbau von leguminosen. Sächsische. Landwirtschaftliche Zeitschrift, 44, pp. 90-92.

Nuti, M. P., Ledeboer, A. M., Lepidi, A. A. y Schilperoort, R. A. (1977). Large plasmids in diferent Rhizobium species. Journal of General Microbiology, 100, pp. 241-248. http://dx.doi. org/10.1099/002212871002241

Orla-Jensen, S. (1909). Die Hauptlinien des Natürlichen Bacteriensystems nebst einer Uebersicht der Gärungsphenomene. Zentralblatt für Bacteriologie Parasitenkunds Infectionskrankheiten und Hygiene Ableitung, II Bd 22, pp. 305-346.

Rogel, M. A., Ormeño-Orrillo, E. y Martinez-Romero, E. (2011). Symbiovars in rhizobia reflect bacterial adaptation to legumes. Systematic and Applied Microbiology, 34, pp. 96-104. http:// dx.doi.org/10.1016/j.syapm.2010.11.015

Peix, A., Ramírez-Bahena, M. H., Velázquez, E. y Bedmar, E. J. (2015). Bacterial asociations with legumes. CRC Critical Reviews in Plant Sciences, 34, pp. 17-42. http://dx.doi.org/10.1080/07352689.2 014.897899

Peters, N. K., Frost, J. W. y Long, S. R. (1986). A plant flavone, luteolin, induces expression of Rhizobium meliloti nodulation genes. Science, 233, pp. 977-980. http://dx.doi.org/10.1126/ science. 3738520

Prazmowski, A. (1890). Die wurzelknöllchen der erbse. Landwirtschaflichen Versuchsstat, 37, pp. 161-238. 
Prescott, L. M., Harley, J. P. y Klein, D. A. (2004). Microbiología. Madrid: McGraw-Hill Interamericana.

Price, N. P., Relić, B., Talmont, F., Lewin, A., Promé, D., Pueppke, S. G., Maillet, F., Dénarié, J. Promé, J. C., Broughton, W. J. (1992). Broad-host-range Rhizobium species strain NGR234 secretes a family of carbamoylated, and fucosylated, nodulation signals that are O-acetylated or sulphated. Molecular Microbiology, 6, pp. 3575-3584. http://dx.doi.org/10.1111/j.13652958.1992. tb01793.x

Ramírez-Bahena, M. H., García-Fraile, P., Peix, A., Valverde, A., Rivas, R., Igual, J. M., Mateos, P. F., Martínez-Molina, E. y Velázquez, E. (2008). Revision of the taxonomic status of the species Rhizobium leguminosarum (Frank 1879) Frank 1889, Rhizobium phaseoli Dangeard 1926AL and Rhizobium trifolii Dangeard 1926AL. $R$. trifolii is a later synonym of $R$. leguminosarum. Reclassification of the strain Rhizobium leguminosarum DSM 30132T (=NCIMB $11478 \mathrm{~T}$ ) into the new species Rhizobium pisi sp. nov. International Journal of Systematic and Evolutionary Microbiology, 58, pp. 2484-2490. http://dx.doi.org/10.1099/ijs.0.656210

Schindler, F. (1885). Über die biologische bedeutung der wurzelknöllchen bei den Papilionaceen. Journal die Landwirtschaft, 33, pp. 325-336.

Schlaman, H. R. M., Spaink, H. P., Okker, R. J. H. y Lugtenberg, B. J. J. (1989). Subcellular localization of the nodD gene product in Rhizobium leguminosarum. Journal of Bacteriology, 171, pp. 4686-4693.

Schlegel, H. G. (1990). Microbiología General. Barcelona: Ediciones Omega.

Schmidt, J., Wingender, R., John, M., Wieneke, U. y Schell, J. (1988). Rhizobium meliloti nod $A$ and nod $B$ genes are involved in generating compounds that stimulate mitosis of plant cells. Proceedings of the National Academy of Sciences of U. S. A., 85, pp. 8578-8582. http://dx.doi.org/10.1073/pnas.85.22.8578
Török, I. y Kondorosi, A. (1981). Nucleotide sequence of Rhizobium meliloti nitrogenase reductase (nifH) gene. Nucleic Acids Research, 9, pp. 5711-5723. http://dx.doi.org/10.1093/ nar/9.21.5711

Vinuesa, P., Silva, C., Lorite, M. J., Izaguirre-Mayoral, M. L., Bedmar, E. J. y Martínez-Romero, E. (2005). Molecular systematics of rhizobia based on maximum likelihood and Bayesian phylogenies inferred from $r r s, a t p D, \operatorname{rec} A$ and nifH sequences, and their use in the classification of Sesbania microsymbionts from Venezuelan wetlands. Systematic and Applied Microbiology, 28, pp. 702-716. http://dx.doi.org/10.1016/j.syapm.2005.05.007

Ward, H. M. (1887). On the tubercular swellings on the root of Vicia faba. Philosophical Transactions B, 178, pp. 539-562. http:// dx.doi.org/10.1098/rstb.1887.0018

Woese, C. R. y Fox, G. E. (1977). Phylogenetic structure of the procaryotic domain: The primary kingdoms. Proceedings of the $\mathrm{Na}$ tional Academy of Sciences of U. S. A., 74, pp. 5088-5090. http:// dx.doi.org/10.1073/pnas.74.11.5088

Woese, C. R., Kandler, O. y Wheels M.L. (1990) Towards a natural system of organisms: proposal for the domains of Archaea, Bacteria, and Eucarya. Proceedings of the National Academy of Sciences of U. S. A., 87, pp. 4576-4579. http://dx.doi.org/10.1073/ pnas.87.12.4576

Yanni, Y. G., Rizk, R.Y., Corich, V., Squartini, A., Ninke, K., Philip-Hollingsworth, S., Orgambide, G., de Bruijn, F., Stoltzfus, J., Buckley, D., Schmidt, T. M., Mateos, P. F., Ladha, J. K. y Dazzo, F. B. (1997). Natural endophytic association between Rhizobium leguminosarum bv. trifolii and rice roots and assessment of its potential to promote rice growth. Plant and Soil, 194, pp. 99-114. http:// dx.doi.org/10.1023/A:1004269902246 